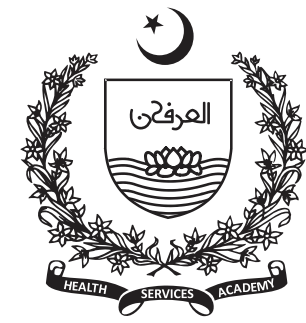

${ }^{1}$ CIMS Multan.

2 Deptt of Paediatrics, $\mathrm{CMH}$

Rawalpindi,

${ }^{3}$ Deptt of Pharmacology, AM College Rawalpindi

4 Deptt of Home and Health Sciences, AIOU Islamabad.

${ }^{5}$ Deptt of Home and Health Sciences, AIOU Islamabad.

${ }^{6}$ Deptt of Pharmacology, AM College Rawalpindi.

Corresponding Author: Muhammad Faisal Afridi Email: fafidi@gmail.com

\section{Prevalence of Intestinal Parasitic Infestation among Pre-school Children in Skardu, Pakistan}

\author{
Muhammad Faisal Afridi ${ }^{1}$, Arshad Khushdil2, Kulsoom Farhat ${ }^{3}$, \\ Zaheer Ahmed ${ }^{4}$, Hajra Ahmed ${ }^{5}$, Shabana Ali ${ }^{6}$
}

\section{Abstract}

Background: World Health Organization (WHO) reports that around 270 million pre-school children and over six hundred million school children are likely to be infested with one or more types of the intestinal worms. The helminthic infestations are indicators of the low socioeconomic status, lack of education, lack of good hygienic conditions and inaccessibility to potable water. Our study aimed to estimate prevalence of intestinal parasitic infections among 1 to 5 years old children residing in the district Skardu of Gilgit Baltistan, Pakistan.

Methods: A descriptive, cross-sectional study was carried out on pre-school children of the district Skardu from August 2016 to January 2017. A sample of 300 children was obtained using non-probability convenience sampling technique. Demographical data was obtained through the structured questionnaire. The stool sample was collected and examined for intestinal parasites. The data was analysed using SPSS.

Results: The prevalent intestinal helminths were found to be Ascaris Lumbricoides, Cryptosporidium , Hymenolepis Nana and Giardia with proportion of $22.33 \%, 14.0 \%, 9.3 \%$ and $8.0 \%$ respectively in our study population. $85 \%$ children of the sample belonged to low or lower middle socioeconomic (SE) groups; correspondingly, increased prevalence of intestinal helminthic infestation was noted in the same SE groups.

Conclusion: A high prevalence of these parasitic infections have been found in the children in Sakardu, which increases with age as the children start eating by themselves.

Keywords: Ascaris lumbricoides; intestinal parasites; pre-school children; stool RE

\section{Introduction}

$\mathrm{I}$ ntestinal parasites also called helminths often occur in low socioeconomic areas. Such infections are amongst the most ignored diseases of the tropical region and constitute a major problem in respect to pubiic heaith in such areas[i]. Due to the poor environmental conditions and defective disposal of human feces, these infections are most common among the children of such areas. They may not necessarily produce serious disease in the human host, but indirectly rob the individual of his energy, 
interfere with his nutrition and ultimately make him susceptible to other diseases [2]. This not only deprives an individual of his health, but it ultimately deprives the country from useful resources, burdening the economic stability of a country. Particularly in remote areas of Pakistan, like Baltistan, where there is limited access of health facilities, are at risk of being neglected and more so children of that areas, who have number of health problems. These health issues may not be very significant in the areas where access to all levels of healthcare is available; but such issues like, intestinal parasitic infestation and malnutrition get augmented for people living in the tough terrains and mountainous areas like Baltistan. This study was planned with the same thinking at the back of mind.

The soil transmitted helminths include Ascaris lumbricoides, Trichuris trichiura and hookworms, and these are the most common intestinal parasites [3]. Of these the commonest one is the Ascaris lumbricoides that infects about 1 billion people worldwide [4] followed by Hymenolepis nana and Giardia lamblia, [5,6]. Usually it has been observed that the children are affected the most because of their unhealthy behaviors including their frequent handling and playing with infested soils. They are less careful while they ingest food with hands that are dirty, more often consume what remains contaminated and above all the bathroom practices that remain unhygienic. Much studies carried out in school-aged children have documented the associations between these infections and the poor nutritional status. Both the underdeveloped and the developed countries frequently face great morbidity and mortality at the hands of protozoan diarrhea caused by these parasites. About 39 million disability adjusted life years (DALYs) are attributed to these infections and thus represent a substantial economic burden [7].

The present study was conceived with the prime motivation to contribute towards estimation of intestinal parasitic infestation in poor people living in remotest northern areas of Pakistan i.e. Skardu. There is a dire need to identify, understand, quantify and prioritize the health, hygiene and nutritional problems of this rugged mountainous area. This study is one such endeavor. Of all the people, children of this area are especially neglected parts of any such population. If we estimate the extent of intestinal parasitic infestation we can have a fair idea of the social, healthcare facilities and hygienic conditions of this area.

\section{Methodology}

This was a community based, Descriptive, Cross sectional study. It was conducted in Baltistan region in the remotest Northern Areas of Pakistan from August 2016 to January 2017. This sample size was determined using online Raosoft calculator; keeping confidence level at $95 \%$ and margin of error at $5 \%$. A sample of 300 children was selected by using non-probability convenience sampling technique. The sample included children both male and female, of preschool age group. Although there is no standard definition of preschool age group, however in cultural set up of Baltistan children are usually not sent to school before 5 years of age. Therefore, the upper cut off point of children age was 5 years. Those children with chronic illnesses or congenital anomalies were excluded from the study. Similarly, those were also excluded whose parents/guardians refused to participate in the study. Informed consent was obtained from the parents and the study was conducted after getting the approval of the ethical committee.

Structured questionnaire was used to obtain demographic and other data; which was filled by the parents/guardians of children. All this data was obtained by a trained research officer on the questionnaire which was addressed to the parents. The specimen bottles along with all the relevant instructions were given to the parents of the child a day prior to study, properly labelled with name and identification number. The parents were guided as to how and when the sample be collected. It was collected for the microbiological data by observing intestinal parasites and for this stool routine examination was done. The laboratory analysis was carried out at Pathology department of a healthcare facility. The direct fecal examination was done on the fresh specimen for ova/cyst of helminths and saline iodine staining for the detection of protozoa. Two slides were prepared per sample; approximately $7 \%$ of all slides were re-read for quality control. They were microscopically examined initially under low power field then under high power bright field. The children having a stool test positive were also provided with anti-parasitic treatment. Albendazole and/or metronidazole were given as treatment under consultation of a physician.

The questionnaires were checked on routine basis in order to complete the missing data. The data thus collected was later analysed using SPSS. 
Wherever the variables be required to be categorized, were done so. The mean and standard deviation were used to describe the continuous variables. For computing categorical variables, proportion was used. The associations were measured by student's $t$ test or chi square test. The $p$ value of 0.05 was considered as significant.

\section{Results}

The proportion of male and female children among the study population was $56 \%$ and $44 \%$ respectively. Among the sample of 300 preschool children, 161 (53.67\%) had parasitic infestation and 139 $(46.33 \%)$ had No parasites found in their stools. However this difference is statistically not significant ( $\mathrm{p}$ value $>0.5$ ).

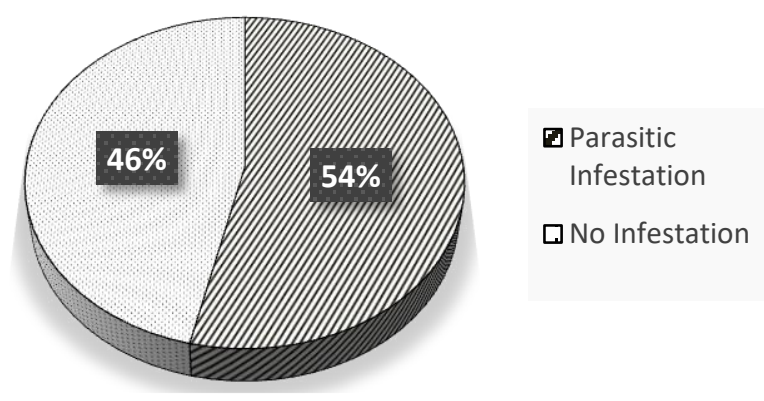

\section{Infestation}

Figure 1. Prevalence of Intestinal Parasitic

The socioeconomic (SE) distribution of the sample is shown in Figure 1. The majority (85\%) of sample belong to Low or Low Middle SE group i.e. 165(55\%) and $90(30 \%)$ respectively. This difference is statistically significant ( $p$ value $<0.0001$ )

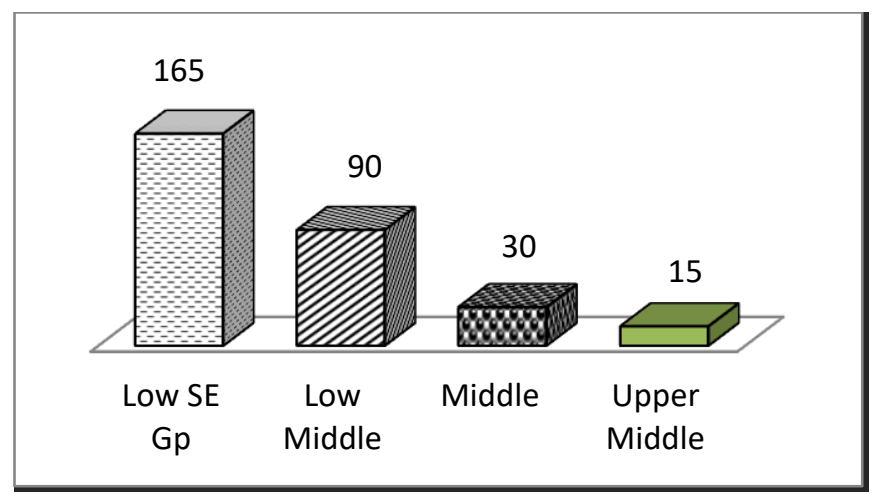

Figure 2. Socioeconomic Distribution

Result of socioeconomic score (SES) in relation to different parasitic infestations is shown in Table 1 . It shows that $25 \%$ and $17.7 \%$ of children belong to low middle and working poor socioeconomic class. The other socioeconomic classes have less percentage proportion for different types of parasite infestation. Moreover, $34.0 \%$ preschool children of working poor class with no parasite infestation in result of demographic analysis shows the overall poverty of the study locale. This is highly significant with $\mathrm{p}$ value $<0.00001$ and chi square statistic of 61.8306 .

Table 1. Parasitic infestation in relation to SES

\begin{tabular}{|l|c|c|c|c|c|c|}
\hline S.E. Class & $\begin{array}{l}\text { No } \\
\text { Parasitis L } \\
\text { e }\end{array}$ & $\begin{array}{l}\text { Ascar } \\
\text { e }\end{array}$ & $\begin{array}{l}\text { H. } \\
\text { nana }\end{array}$ & $\begin{array}{l}\text { Cry } \\
\text { pto }\end{array}$ & $\begin{array}{l}\text { Giar } \\
\text { dia }\end{array}$ & $\begin{array}{l}\text { G.TO } \\
\text { TAL }\end{array}$ \\
\hline Low SE & 106 & 20 & 13 & 18 & 8 & $\mathbf{1 6 5}$ \\
\hline Low Middle & 15 & 34 & 10 & 20 & 11 & $\mathbf{7 1}$ \\
\hline Middle & 13 & 7 & 5 & 3 & 2 & $\mathbf{3 0}$ \\
\hline Upper Middle & 05 & 6 & 0 & 1 & 3 & $\mathbf{1 5}$ \\
\hline \multicolumn{1}{|c|}{ Total } & $\mathbf{1 3 9}$ & $\mathbf{6 7}$ & $\mathbf{2 8}$ & $\mathbf{4 2}$ & $\mathbf{2 4}$ & $\mathbf{3 0 0}$ \\
\hline
\end{tabular}

*(p-value $<0.00001 /$ chi sq 61.8306)

We observed that the children in the age groups of 24-35 months and 36-60 months, formed the major bulk of sample and they had the highest percentage values for parasitic infestations. Among the male preschool children, the percentage of parasite infestation of any kind, was found to be $31 \%$; while among all the female preschool children $22.7 \%$ had parasitic infestation of some kind. Similarly, out of 161 children who had parasitic infestation 93 were male and 68 were female. (Table 2). However gender difference among those with parasitic infestation is also not significant statistically ( $\mathrm{p}$ value 0.590 ).

Table 2. Gender-wise Parasites Infestation in the study sample

\begin{tabular}{|c|c|c|c|c|}
\hline \multirow{2}{*}{ Presence of Parasite } & \multicolumn{2}{|c|}{ Male } & \multicolumn{2}{c|}{ Female } \\
\cline { 2 - 5 } & $\mathbf{N}$ & $\mathbf{\%}$ & $\mathbf{N}$ & $\mathbf{\%}$ \\
\hline Yes & 93 & $31.0 \%$ & 68 & $22.7 \%$ \\
\hline No & 76 & $25.3 \%$ & 63 & $21.0 \%$ \\
\hline Total & $\mathbf{1 6 9}$ & $\mathbf{5 6 . 3} \%$ & $\mathbf{1 3 1}$ & $\mathbf{4 3 . 7} \%$ \\
\hline
\end{tabular}

${ }^{*} p$-value 0.590

The result for analysis of parasite types is based on percentages of overall sample of the study. Result reflects percentage of children infested with Ascaris Lumbricoides is $22.33 \%$; while $14.0 \%$ of children with Cryptosporidium; $9.3 \%$ and $8.0 \%$ with Hymenolepis Nana and Giardia respectively.(Table 3). This difference is statistically significant with $\mathrm{p}$ value $<0.00001$. 
Table 3. Types of Infested Parasites

\begin{tabular}{|l|c|c|}
\multicolumn{1}{|c|}{ Parasite Type } & N & \% \\
\hline Ascaris Lumbricoides & 67 & $22.3 \%$ \\
\hline Hymenolepis Nana & 28 & $9.3 \%$ \\
\hline Cryptosporidium & 42 & $14.0 \%$ \\
\hline Giardia & 24 & $8.0 \%$ \\
\hline Total Parasitic infestation & $\mathbf{1 6 1}$ & $\mathbf{5 3 . 6} \%$ \\
\hline \multicolumn{3}{|c|}{} \\
\hline No Parasitic Infestation & $\mathbf{1 3 9}$ & $\mathbf{4 6 . 4}$ \\
\hline
\end{tabular}

${ }^{*} p$-value is $<0.00001$

\section{Discussion}

This study was conducted in the remote northern area of Pakistan near Skardu which is located at an altitude of nearly 2,500 meters. This area experiences extreme cold weather in winters. Due to this cold weather people especially younger children remain reluctant to maintain hygiene and sanitation. This situation becomes further complicated as there is ample number of domestication of animals at home along with the land farming in small area fields closely located to the populations. That was the main reason for us to conduct the research in such remote area.

In a sample of 300 children, we observed that $53.67 \%$ of the pre-school children had the parasitic infection, with male $(31 \%)$ more prone to worm infestation as compared to female $(22.6 \%)$ children. It was further observed that amongst different age groups the boys above the age of two years were highly subjective to this situation. This means that the children who can eat by themselves are more prone to intestinal parasites.

This situation is also seconded by the studies that report these parasitic infections as a major health problem and a financial burden $[8,9,10]$. We observed that out of a total of 300 children, 161 (53.6\%) were infected with at least one intestinal parasite. Mehraj et al. (2008) also reported infection prevalence of 52.8\% in their study [11]. Present study has observed a higher prevalence of infection as compared to the prevalence of infection in community village Budhni of Peshawar Pakistan [12].

We observed that our sample had the high percentage $(22.33 \%)$ of Ascaris Lumbricoides, moderate percentage $(14.0 \%)$ of Cryptosporidium and low percentages $(9.3 \%$ and $8.0 \%$ ) for Hymenolepis Nana and Giardia respectively. These findings are consistent with the finding of Nishiura et al. (2002) who found a high prevalence of Ascaris Lumbricoides in children of age group 5-8 years residing in the Northern areas of Pakistan [13]. Khan and collegues in
2019 reported 53\% prevalence of Ascaris Lumbricoides in Pakistan and most of them were below the age of 15 years [14].

Choy and colleagues in 2014 have reported the highest prevalence of Giardia Lamblia in their study group [15] but in our study cohort, Giardia was found only in infants with a prevalence of $2.3 \%$. Unlike the results for $\mathrm{H}$. Nana by Abdel et al with a prevalence of $32.6 \%$, our sample had $9.7 \%$ prevalence [16]. In a study conducted in a village Budhni of Peshawar, the prevalence of $\mathrm{H}$. Nana and giardia was found $6 \%$ and $19 \%$ respectively [12]. This was a little different to our finding. The prevalence of intestinal parasites like cryptosporidium and giardia in the current study is comparable to reports of Kimosop and colleagues [17].

Similarly, the study sample of Galgamuwa and colleagues in 2018 also showed highest prevalence of Ascaris Lumbricoides (38.4\%) in children between the age group of 1-12 years [18]. More recently in a study by Khushdil et al. (2016) cryptosporidiosis had a prevalence of $20.8 \%$ in children of Skardu [19]. In another study conducted in the district of Bunir, the prevalence of Cryptosporidium was $29.88 \%$ [14] and we found it to be $15.7 \%$. A study by Mumtaz et al. (2010) came up with the prevalence of Cryptosporidium with a value of $9.0 \%$, being commonly observed in infants ( $<24$ months) [20] but we observed a higher prevalence with broader distribution among all age groups.

We carried out this study to find out the prevalence of these parasites in the children between the age group of 1-5 years in the District Skardu in order to document the major health problem from public health view point of the remotest and inaccessible areas of Pakistan. Due to limitation of resources and time we could not conduct the study at the larger scale. It is suggested that the study be conducted at larger scale, in the northern areas where there is no access through roads; so that actual magnitude of the problems can be estimated.

\section{Conclusion}

A high prevalence of the intestinal parasites has been found in the children in Skardu, which increases with age as the children start eating by themselves. As these infections badly effect the economic and social structure, hampering the overall development of the area, an awareness program and deworming strategy is the need of the hour in the addressed community. 


\section{References}

1. Tegegne $\mathrm{Y}$, Wondmagegn $\mathrm{T}$, Worku L and Zeleke AJ. Prevalence of Intestinal Parasites and Associated Factors among Pulmonary Tuberculosis Suspected Patients Attending University of Gondar Hospital, Gondar, Northwest Ethiopia. J Parasitol Res. 2018; Article ID 9372145, 6 pages, 2018. https://doi.org/10.1155/2018/9372145.

2. Espinosa Aranzales AF, Radon K, Froeschl G, Pinzón Rondón ÁM, Delius M. Prevalence and risk factors for intestinal parasitic infections in pregnant women residing in three districts of Bogotá, Colombia. BMC Public Health. 2018;18(1):1071. doi:10.1186/s12889-0185978-4.

3. Gebretsadik D, Metaferia Y, Seid A et al. Prevalence of intestinal parasitic infection among children under 5 years of age at Dessie Referral Hospital: cross sectional study. BMC Research Notes. 2018;11:771. https://doi.org/10.1186/s13104-018-3888-2.

4. Yang D, Yang Y, Wang Y, et al. Prevalence and Risk Factors of Ascaris lumbricoides, Trichuris trichiura and Cryptosporidium Infections in Elementary School Children in Southwestern China: A School-Based CrossSectional Study. Int J Environ Res Pub Health. 2018;15(9):1809. doi:10.3390/ijerph15091809.

5. Omar S, Amer O, Esam S, Al-Malki, Mohamed I, Waly, Abdulaziz AlAgeel, and Mahmoud Y L. Prevalence of Intestinal Parasitic Infections among Patients of King Fahd Medical City in Riyadh Region, Saudi Arabia: A 5Year Retrospective Study. J Parasitol Res. 2018, Article ID 8076274, 8 pages. https://doi.org/10.1155/2018/8076274.5.

6. Tandukar S, Sherchand J B, Xue J. Prevalence and associated risk factors of Giardia duodenalis infection among school-going children in Nepal. Parasitol Res. 2018;117 (1): 287-293.

7. Stephenson LS, Latham MC, Ottesen EA.Malnutrition and parasitic helminth infections. Parasitology. 2000; 121 Suppl: S23-38.

8. Minetti C, Chalmers R M, Beeching NJ, Probert C, Lamden K. Giardiasis. BMJ : Br Med J. 2016; 355. doi:10.1136/bmj.i5369.

9. Pullan R L and Brooker S J. The global limits and population at risk of soil-transmitted helminth infections in 2010. Parasites \& vectors. 2012; 5(1), 81.

10. Ramana K. Intestinal parasitic infections: An overview. Annals of Tropical Medicine and Public Health. 2012; 5(4), 279-281. doi:10.4103/1755-6783.101988
11. Mehraj V, Hatcher J, Akhtar S, Rafique G and Beg M A. Prevalence and Factors Associated with Intestinal Parasitic Infection among Children in an Urban Slum of Karachi. PLoS ON. 2008; 3(11), e3680.

12. Haider J, Mohammad N, Nazli R, Fatima S and Akhtar T. Prevalence of parasitic infestation in children of a rural community of Peshawar. KMUJ. 2018; 10(1): 14-18.

13. Nishiura $H$, Imai $H$, Nakao $H$, Tsukino $H$, Changazi $M$ A, Hussain G A, Katoh T. Ascaris lumbricoides among children in rural communities in the Northern Area, Pakistan: prevalence, intensity, and associated sociocultural and behavioral risk factors. Acta Tropica. 2002; 83(3):223-231.

14. Khan A, Shams S, Khan S, Khan MI, Khan S, Ali A. Evaluation of prevalence and risk factors associated with Cryptosporidium infection in rural population of district Buner, Pakistan. PLoS ONE. 2019; 14(1): e0209188. https://doi.org/10.1371/journal.pone.020918819

15. Choy SH, Al-Mekhlafi HM, Mahdy MA, et al. Prevalence and associated risk factors of Giardia infection among indigenous communities in rural Malaysia. Sci Rep. 2014; 4: 6909. doi:10.1038/srep06909

16. Abdel HMM, Eljack IA, Osman $M K$ et al. The prevalence of Hymenolepis nana among preschool children of displacement communities in Khartoum state, Sudan: a cross-sectional study.Travel Med Infect Dis. 2015;13(2):172-7.

17. Kimosop RJ, Mulambalah CS, Ngeiywa MM. Prevalence of enteric parasitic diseases among patients referred at a teaching hospital in Kenya. J Health Res Rev. 2018; 5:7885

18. Galgamuwa LS, Iddawela D, Dharmaratne SD. Prevalence and intensity of Ascaris lumbricoides infections in relation to undernutrition among children in a tea plantation community, Sri Lanka: a crosssectional study. BMC Pediatr. 2018;18(1):13. doi:10.1186/s12887-018-0984-3

19. Khushdil A, Murtaza F and Chattha $M$ N. Cryptosporidiosis Among Children Of District Skardu, Pakistan. J Ayub Med Coll. 2016; 28(3), 575-577.21.

20. Mumtaz S, Ahmed J and Ali L. Frequency of cryptosporidium infection in children under five years of age having diarrhea in the North West of Pakistan. African Journal of Biotechnology. 2010; 9(8). 